ARTICLE

DOI: $10.1038 / \mathrm{s} 41467-017-01101-6$

\title{
Firefly-mimicking intensive and long-lasting chemiluminescence hydrogels
}

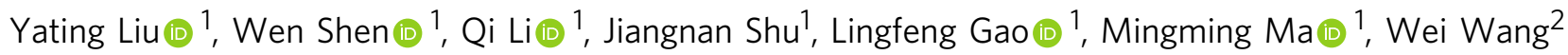 \\ \& Hua Cui(i) ${ }^{1}$
}

Most known chemiluminescence $(\mathrm{CL})$ reactions exhibit flash-type light emission. Great efforts have been devoted to the development of $C L$ systems that emit light with high intensity and long-lasting time. However, a long-lasting CL system that can last for hundreds of hours is yet-to-be-demonstrated. Here we show firefly-mimicking intensive and longlasting $\mathrm{CL}$ hydrogels consisting of chitosan, $\mathrm{CL}$ reagent $\mathrm{N}$-(4-aminobutyl)- $\mathrm{N}$-ethylisoluminol (ABEI) and catalyst $\mathrm{Co}^{2+}$. The light emission is even visible to naked eyes and lasts for over $150 \mathrm{~h}$ when the hydrogels are mixed with $\mathrm{H}_{2} \mathrm{O}_{2}$. This is attributed to slow-diffusion-controlled heterogeneous catalysis. $\mathrm{Co}^{2+}$ located at the skeleton of the hydrogels as an active site catalyzes the decomposition of slowly diffusing $\mathrm{H}_{2} \mathrm{O}_{2}$, followed by the reaction with $\mathrm{ABEl}$ to generate intensive and long-lasting $\mathrm{CL}$. This mimics firefly bioluminescence system in terms of intensity, duration time and catalytic characteristic, which is of potential applications in cold light sources, bioassays, biosensors and biological imaging.

\footnotetext{
${ }^{1}$ CAS Key Laboratory of Soft Matter Chemistry, Collaborative Innovation Center of Chemistry for Energy Materials, Department of Chemistry, University of Science and Technology of China, Hefei, Anhui 230026, China. ${ }^{2}$ School of Chemistry and Chemical Engineering, State Key Laboratory of Analytical Chemistry for Life Science, Nanjing University, Nanjing, Jiangsu 210093, China. Yating Liu, Wen Shen and Qi Li contributed equally to this work. Correspondence and requests for materials should be addressed to H.C. (email: hcui@ustc.edu.cn)
} 
ight emission induced by chemical reactions, known as chemiluminescence (CL), has been intensively investigated for many years. It has been widely applied in cold light sources, bioassays, reporter genes, biological imaging, and biomapping ${ }^{1-4}$. However, most known CL reactions exhibit flashtype light emissions, which hampers their applications. Light emission with high intensity and long-lasting time, i.e., glow-type emission, has been the holy grail of CL field. For example, strong and long-lasting emission are crucial for cold light sources in emergency situations, decorative entertainment, and underwater lighting. In analytical chemistry fields, the CL reactions with flashtype emission generally carry out CL emission in seconds or minutes and possess a fast kinetic curve, which would lead to poor analytical accuracy. The glow-type emission can produce a slow kinetic curve, even a constant emission within analytical time, which would improve greatly the analytical sensitivity and accuracy $^{5}$. Besides, CL is less often used for imaging than fluorescence due to the lack of strong and long-lasting CL probes ${ }^{4,6}$. Strong and long-lasting emission is beneficial for the investigation in the field of CL imaging with microscopy. In the past, enzyme-involved $\mathrm{CL}$ reactions are main CL systems producing long-lasting emission. For enzymatic reactions such as firefly bioluminescence (BL) system, bacterial BL system, alkaline phosphatase-3-(2'-spiroadamantane)-4-methoxy-4-(3" - phosphoryloxy)phenyl-1,2-dioxetane system and luminol- $\mathrm{H}_{2} \mathrm{O}_{2}$-peroxidases system, long-lasting emission arose from the turnover of the enzymes and excessive substrates $^{7-9}$. However, enzyme inactivation was the main reason for light decay in the above CL systems ${ }^{10}$. Besides, peroxyoxalate ester CL system could also produce long-lasting emission under controlled conditions. The nucleophilic reaction of hydrogen peroxide with peroxyoxalate esters to generate a high energy intermediate dioxetandione is the rate-determining step for the CL reaction. The activated intermediate complex formed by dioxetandione and fluorophore can be continuously produced by a

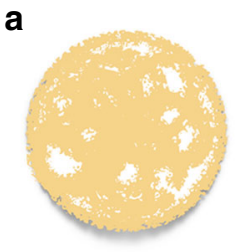

CS

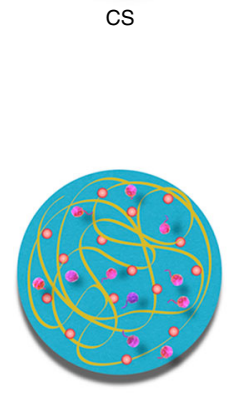

$\mathrm{ABEI} / \mathrm{Co}^{2+} / \mathrm{CS}$ hydrogels

b

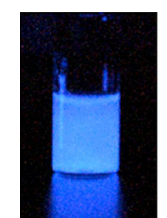

$0.5 \mathrm{~h}$

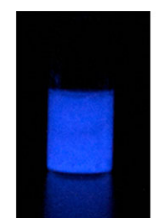

$12 \mathrm{~h}$

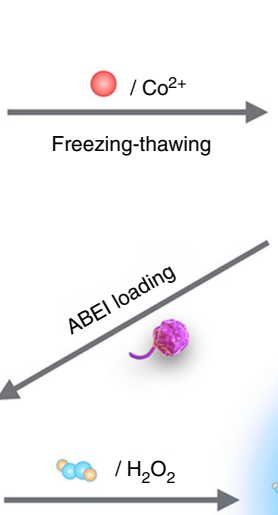

$\mathrm{Co}^{2+} / \mathrm{CS}$ hydrogels

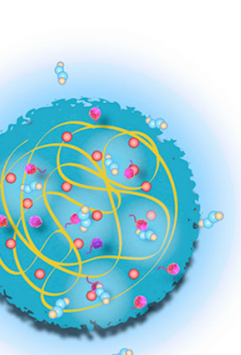

$\mathrm{ABEl} / \mathrm{Co}^{2+} / \mathrm{CS}$ hydrogels

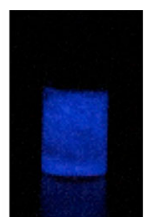

$48 \mathrm{~h}$

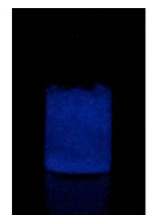

$120 \mathrm{~h}$

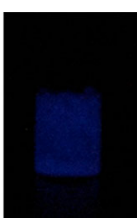

$150 \mathrm{~h}$
Fig. 1 Schematic illustration. a Preparation of $\mathrm{ABEl} / \mathrm{Co}^{2+} / \mathrm{CS}$ hydrogels. b $\mathrm{CL}$ emission of $\mathrm{ABEl} / \mathrm{Co}^{2+} / \mathrm{CS}$ hydrogels succeeding supply of excess oxalate and fluorophore ${ }^{9}$. Since then, no new long-lasting CL mechanism has been discovered for a long time. Intensive and long-lasting CL emission is highly desired for sensitive and accurate bioassays, cold light sources and CL imaging, but is still a great challenge.

Herein, we report an intensive and long-lasting CL chitosan (CS) hydrogel with CL reagent $\mathrm{N}$-(4-aminobutyl)-N-ethylisoluminol (ABEI) and catalyst $\mathrm{Co}^{2+}\left(\mathrm{ABEI} / \mathrm{Co}^{2+} / \mathrm{CS}\right.$ hydrogels $)$ by virtue of a slow-diffusion-controlled heterogeneous catalytic mechanism, which mimics the firefly BL system in terms of both catalytic and kinetic characteristics. The light emission is even visible to naked eyes and lasts for over $150 \mathrm{~h}$.

\section{Results}

Synthesis and characterizations. The preparation of $\mathrm{ABEI} / \mathrm{Co}^{2+} / \mathrm{CS}$ hydrogels is shown in Fig. 1a. Initially, chitosan powders dispersed in alkaline solution were mixed with $\mathrm{CoCl}_{2}$ solution. Through freezing-thawing process ${ }^{11}, \mathrm{Co}^{2+} / \mathrm{CS}$ hydrogels were obtained. Next, ABEI alkaline solution was mixed with $\mathrm{Co}^{2+} / \mathrm{CS}$ hydrogels and stirred to obtain $\mathrm{ABEI} / \mathrm{Co}^{2+} / \mathrm{CS}$ hydrogels. The as-prepared hydrogels were characterized by scanning electronic emission (SEM), rheology experiments, inductively coupled plasma atomic emission spectroscopy (ICP-AES) and UV-visible absorption spectra.

As shown in Fig. 2a, $\mathrm{Co}^{2+} / \mathrm{CS}$ hydrogels (10 times dilution) possessed porous sponge-like structure with lots of micro-sized and even nano-sized pores, which are consistent with those of previously reported CS hydrogel ${ }^{11,12}$. The porosity of the hydrogels was determined to be $86 \%$. The sponge-like structure with high porosity was endowed with high adsorption capacity for fluids. Moreover, these pores were effective channels for loading small molecules. Therefore, it is reasonable to assume that this porous structure is a wonderful storage of small molecules. The viscoelastic properties of $\mathrm{ABEI} / \mathrm{Co}^{2+} / \mathrm{CS}$ hydrogels were studied by rheology experiments. After setting the strain amplitude at $1 \%$ (within the linear response of strain amplitude as shown in Supplementary Fig. 1), dynamic frequency sweep of $\mathrm{ABEI} / \mathrm{Co}^{2+} / \mathrm{CS}$ hydrogels was carried out. As shown in Fig. 2b, the dynamic storage modulus $\left(\mathrm{G}^{\prime}\right)$ and loss modulus $\left(\mathrm{G}^{\prime \prime}\right)$ increased with the increase of the frequency from 0.1 to $10 \mathrm{~Hz}$, and $\mathrm{G}^{\prime}$ was 3-4 times higher than $\mathrm{G}^{\prime \prime}$ at the same frequency. This is consistent with the observation that the materials possessed a gel-like structure that barely flowed (test tubes could be tilted upside down without sample flowing, see inset in Fig. 2b). Moreover, the CS hydrogels formed mainly by physical crosslinking ${ }^{13}$ are translucent, thus they are solvent-incompatible system. This is consistent with the fact that CS has a low solubility in alkaline aqueous solution ${ }^{14}$.
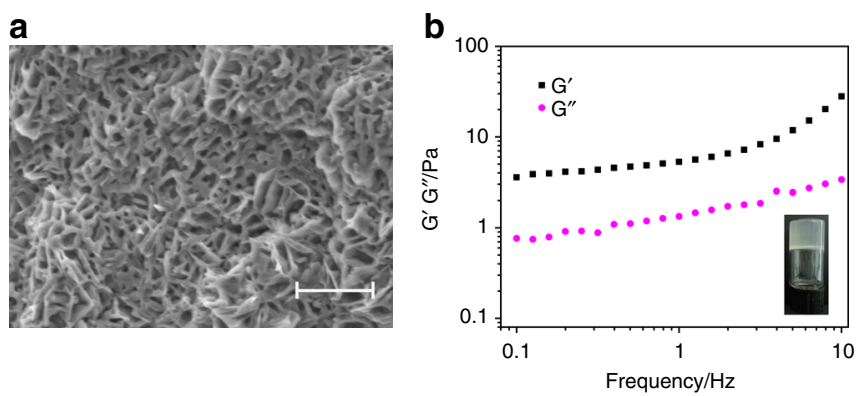

Fig. 2 Characterization of $\mathrm{CO}^{2+} / \mathrm{CS}$ hydrogels and $\mathrm{ABEI} / \mathrm{Co}^{2+} / \mathrm{CS}$ hydrogels. a SEM images of freeze-dried $\mathrm{Co}^{2+} / \mathrm{CS}$ hydrogels with 10 -folds dilution. Scale bar is $10 \mu \mathrm{m}$. b Frequency dependence of dynamic storage modulus ( $\mathrm{G}^{\prime}$ ) and loss modulus (G") of $\mathrm{ABEI} / \mathrm{Co}^{2+} / \mathrm{CS}$ hydrogels with $1 \%$ strain at $20^{\circ} \mathrm{C}$. Inset in Fig. 2b: optical image of $\mathrm{ABEl} / \mathrm{Co}^{2+} / \mathrm{CS}$ hydrogels 

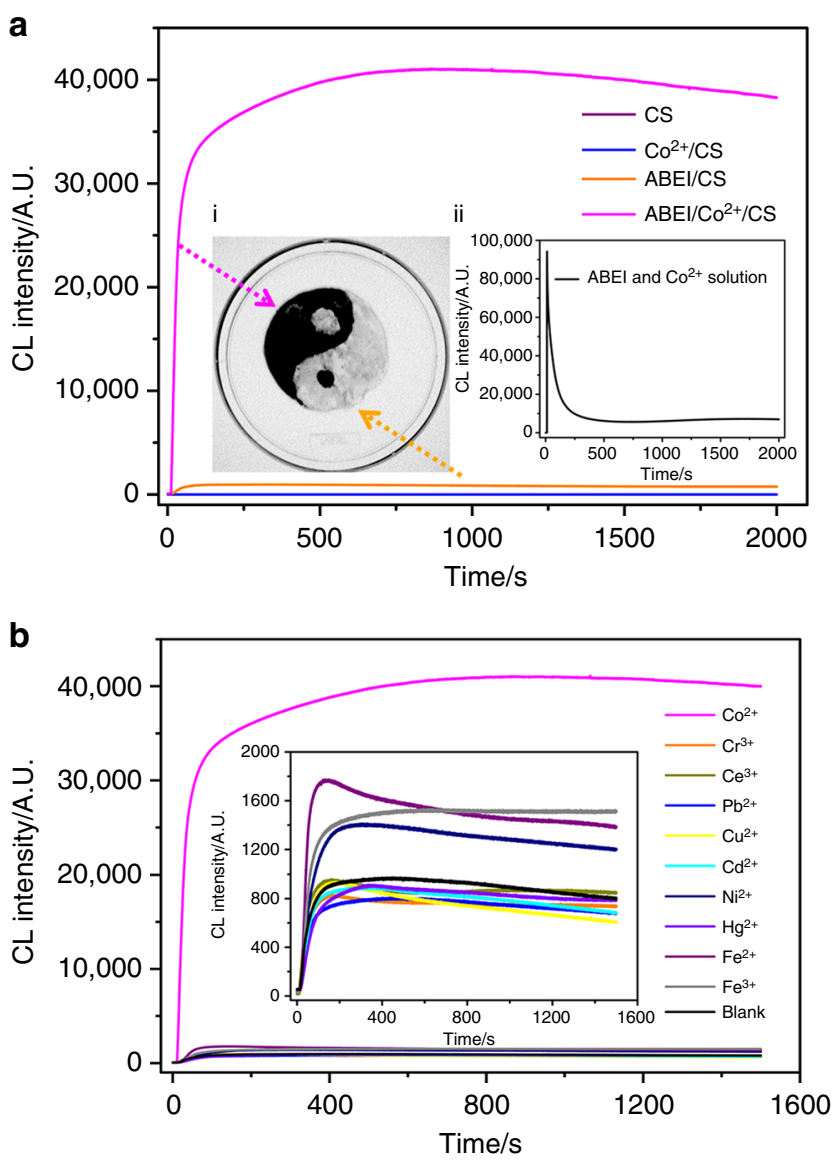

Fig. $3 \mathrm{CL}$ performance. a $\mathrm{CL}$ kinetic curves for reaction of CS hydrogels, $\mathrm{Co}^{2+} / \mathrm{CS}$ hydrogels, $\mathrm{ABEl} / \mathrm{CS}$ hydrogels, $\mathrm{ABEl} / \mathrm{Co}^{2+} / \mathrm{CS}$ hydrogels with $\mathrm{H}_{2} \mathrm{O}_{2}$. Inset (i): gel $\mathrm{CL}$ imaging of $\mathrm{ABEl} / \mathrm{Co}^{2+} / \mathrm{CS}$ hydrogel- $\mathrm{H}_{2} \mathrm{O}_{2}$ (black) and $\mathrm{ABEI} / \mathrm{CS}$ hydrogel- $\mathrm{H}_{2} \mathrm{O}_{2}$ (white). Inset (ii): $\mathrm{CL}$ kinetic curves for reaction of $\mathrm{Co}^{2+}-\mathrm{ABEI}-\mathrm{H}_{2} \mathrm{O}_{2}$ system with a fixed photomultiplier tube (PMT) voltage of $-450 \mathrm{~V}$. b CL kinetic curves for reaction of $\mathrm{ABEl} /$ metal ion/CS hydrogels using different metal ions $\left(\mathrm{Co}^{2+}, \mathrm{Cu}^{2+}, \mathrm{Pb}^{2+}, \mathrm{Ni}^{2+}, \mathrm{Hg}^{2+}\right.$, $\mathrm{Cr}^{3+}, \mathrm{Ce}^{3+}, \mathrm{Cd}^{2+}, \mathrm{Fe}^{2+}, \mathrm{Fe}^{3+}$ and blank) with $\mathrm{H}_{2} \mathrm{O}_{2}$. Inset: magnification of $\mathrm{Cu}^{2+}, \mathrm{Pb}^{2+}, \mathrm{Ni}^{2+}, \mathrm{Hg}^{2+}, \mathrm{Cr}^{3+}, \mathrm{Ce}^{3+}, \mathrm{Cd}^{2+}, \mathrm{Fe}^{2+}, \mathrm{Fe}^{3+}$ and blank (without metal ion) in the $\mathrm{ABEl} /$ metal ion/CS hydrogels $-\mathrm{H}_{2} \mathrm{O}_{2}$. Reaction condition: $100 \mu \mathrm{l} 0.1 \mathrm{M} \mathrm{H}_{2} \mathrm{O}_{2}, 100 \mu$ l hydrogels, $-550 \vee \mathrm{PMT}$

The composition of the hydrogels was characterized. ICP-AES elemental analysis showed the existence of Co. As shown in Supplementary Fig. 2, the characteristic absorption peaks of pure ABEI appeared at around 290 and $320 \mathrm{~nm}$. The $\mathrm{Co}^{2+} / \mathrm{CS}$ hydrogels did not have obvious characteristic absorption peaks. The two characteristic absorption peaks of ABEI at 291 and 320 $\mathrm{nm}$ were also observed in the UV/visible spectrum of $\mathrm{ABEI} / \mathrm{Co}^{2}$ +/CS hydrogels, indicating the existence of ABEI molecules in $\mathrm{ABEI} / \mathrm{Co}^{2+} / \mathrm{CS}$ hydrogels. Therefore, both ABEI and $\mathrm{Co}^{2+}$ were successfully entrapped into the hydrogels. The ABEI and $\mathrm{Co}^{2+}$ used for synthesis were all trapped inside the hydrogels because no further separation treatment of the as-prepared hydrogels was conducted after synthesis.

CL performance. When $\mathrm{ABEI} / \mathrm{Co}^{2+} / \mathrm{CS}$ hydrogels reacted with $\mathrm{H}_{2} \mathrm{O}_{2}$ solution, firefly-mimicking intensive and long-lasting CL emission appeared, as shown in Fig. 1b. The light emission could be observed even by naked eyes in a dark room and lasted for over $150 \mathrm{~h}$. The CL kinetic behavior of $\mathrm{ABEI} / \mathrm{Co}^{2+} / \mathrm{CS}$ hydrogels was further investigated by static injection as shown in Fig. $3 \mathrm{a}$. $100 \mu \mathrm{l}$ of the hydrogels was injected into $100 \mu \mathrm{l}$ of $0.1 \mathrm{M} \mathrm{H}_{2} \mathrm{O}_{2}$ solution. Strong and long-lasting light emission was observed from $\mathrm{ABEI} / \mathrm{Co}^{2+} / \mathrm{CS}$ hydrogels (magenta curve), while no light emission from CS hydrogels (purple curve) and $\mathrm{Co}^{2+} / \mathrm{CS}$ hydrogels (blue curve). The $\mathrm{CL}$ spectrum of $\mathrm{ABEI} / \mathrm{Co}^{2+} / \mathrm{CS}$ hydrogels with $\mathrm{H}_{2} \mathrm{O}_{2}$ exhibited a peak centered at $\sim 440 \mathrm{~nm}$, as shown in Supplementary Fig. 3, which was consistent with that of the CL reaction of ABEI with $\mathrm{H}_{2} \mathrm{O}_{2}{ }^{15}$. These results demonstrated that the CL reaction of ABEI with $\mathrm{H}_{2} \mathrm{O}_{2}$ was responsible for the light emission. $\mathrm{Co}^{2+}$ was further found to enhance the $\mathrm{CL}$ intensity by 40 times when comparing the CL intensities in the presence (magenta curve) and absence (orange curve) of $\mathrm{Co}^{2+}$. The CL signal of $\mathrm{ABEI} / \mathrm{Co}^{2+} / \mathrm{CS}$ hydrogels was not only strong, but also stable for over $25 \mathrm{~min}$ (the CL intensity only decreased to $93 \%$ of the maximum value in $25 \mathrm{~min}$ ). The CL emission was recorded by gel CL imaging as shown in inset (i) of Fig. 3a. Based on the high contrast of ABEI/CS hydrogels and ABEI/Co ${ }^{2+} / \mathrm{CS}$ hydrogels in CL intensity, traditional Chinese Taiji pattern was painted. ABEI/CS hydrogels showed a weak CL (white part) while $\mathrm{ABEI} / \mathrm{Co}^{2+} / \mathrm{CS}$ hydrogels a strong CL (black part). When $\mathrm{Co}^{2+}$ and ABEI solutions were directly mixed with $\mathrm{H}_{2} \mathrm{O}_{2}$ in alkaline solution, a flash CL emission was obtained as shown in inset (ii) of Fig. 3a. The CL reaction kinetic of the $\mathrm{Co}^{2+}-\mathrm{ABEI}-\mathrm{H}_{2} \mathrm{O}_{2}$ system is quite different from those of $\mathrm{ABEI} / \mathrm{Co}^{2+} / \mathrm{CS}$ hydrogel$\mathrm{H}_{2} \mathrm{O}_{2}$. The results demonstrated that the formation of hydrogels affected the CL reaction kinetic of $\mathrm{Co}^{2+}$ - catalyzed $\mathrm{ABEI}-\mathrm{H}_{2} \mathrm{O}_{2}$ system and played an important role in intensive and long-lasting CL. The stability of trapped ABEI and the sustainability of the hydrogel system were also studied by determining fluorescence intensity of ABEI and CL intensity of the hydrogels with $\mathrm{H}_{2} \mathrm{O}_{2}$ as functions of time, as shown in Supplementary Figs. 4 and 5. The results demonstrated that trapped $\mathrm{ABEI}$ and the hydrogels were stable in at least 30 days.

The proposed long-lasting CL system is compared with other non-enzymatic and enzymatic CL systems. Peroxyoxalate esters and firefly $\mathrm{BL}$ are typical non-enzymatic and enzymatic CL systems for long-lasting CL emission, respectively. In the peroxyoxalate ester systems, light emission of bis(6-alkoxycarbonyl-2,4-dichlorophenyl) oxalates could last more than $12 \mathrm{~h}$ with low-intensity ${ }^{16}$. In firefly BL, typical emission could last for more than $6 \mathrm{~h}$ when firefly luciferase was in live cells and $2 \mathrm{~h}$ when firefly luciferase was in solution ${ }^{17,18}$. The light emission of our CL system was even visible to naked eyes and lasted for over 150 h. Accordingly, our system have distinguished CL intensity and duration time, which superior to non-enzymatic peroxyoxalate ester CL system and enzymatic firefly BL system.

It has been reported that various metal ions could catalyze the $\mathrm{CL}$ reactions of luminol and its analogues with $\mathrm{H}_{2} \mathrm{O}_{2}{ }^{19}$. Thus, instead of $\mathrm{Co}^{2+}$, other metal ions $\mathrm{Cu}^{2+}, \mathrm{Pb}^{2+}, \mathrm{Ni}^{2+}, \mathrm{Hg}^{2+}, \mathrm{Cr}^{3+}$, $\mathrm{Ce}^{3+}, \mathrm{Cd}^{2+}, \mathrm{Fe}^{2+}$ and $\mathrm{Fe}^{3+}$ were used to prepare the CS hydrogels. As shown in Fig. 3b, compared with $\mathrm{ABEI} / \mathrm{CS}$ hydrogels without any metal ions, the CL intensity using $\mathrm{Co}^{2+}, \mathrm{Fe}^{3+}, \mathrm{Fe}^{2+}, \mathrm{Ni}^{2+}$, $\mathrm{Ce}^{3+}, \mathrm{Cu}^{2+}, \mathrm{Hg}^{2+}, \mathrm{Cd}^{2+}, \mathrm{Cr}^{3+}$ and $\mathrm{Pb}^{2+}$ changed by $4126,82,57$, $45,-2,-4,-6,-8,-15,-17 \%$, respectively. ABEI/Co ${ }^{2+} / \mathrm{CS}$ hydrogels exhibited unique CL enhancement among all the tested metal ions. Other metal ions of Group VIII in periodic table also showed enhancement to some extent and the rest of the aforementioned ions did not significantly affect CL intensity. Therefore, the CL hydrogels using $\mathrm{Co}^{2+}$ are optimal for achieving intensive CL emission.

Optimization for $\mathbf{C L}$ conditions. Some important parameters affecting the intensity and duration time of CL emission and the formation of the hydrogels, including the concentration of ABEI and $\mathrm{Co}^{2+}$, were studied. As shown in Supplementary Figs. 6 and 7 , the CL intensity increased with the increase of ABEI and $\mathrm{Co}^{2+}$ 

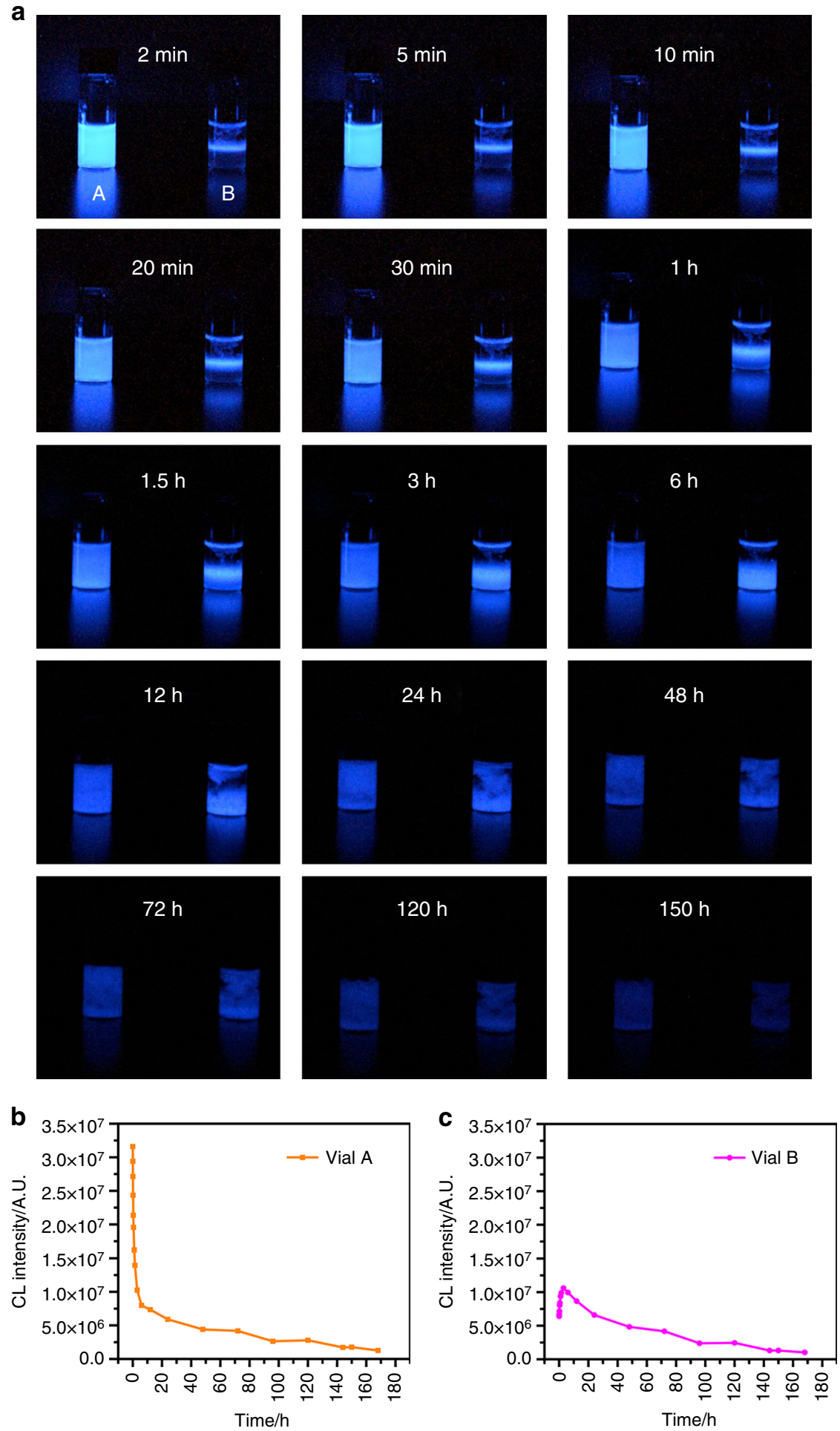

Fig. 4 Reaction of $\mathrm{ABEl} / \mathrm{Co}^{2+} / \mathrm{CS}$ hydrogels with $\mathrm{H}_{2} \mathrm{O}_{2}$ at different times. a Optical images using a digital camera. $\mathrm{H}_{2} \mathrm{O}_{2}$ solution was fully mixed with $\mathrm{ABEl} / \mathrm{Co}^{2+} / \mathrm{CS}$ hydrogels in vial $\mathrm{A}$ and $\mathrm{H}_{2} \mathrm{O}_{2}$ solution was directly added into $\mathrm{ABEl} / \mathrm{Co}^{2+} / \mathrm{CS}$ hydrogels without agitation in vial $\mathrm{B}$. All the images are coded according to the same intensity scale. b, $\mathbf{c ~ C L}$ intensity as a function of time for vial $A$ and $B$, respectively. For $A B E l / \mathrm{Co}^{2+} / C S$ hydrogels, $40 \mathrm{mM} 1.5 \mathrm{ml} A B E l$, $1 \mathrm{mM} 0.6 \mathrm{ml} \mathrm{Co}^{2+}, 15 \mathrm{ml} \mathrm{CS}$ dispersed in alkaline solution. Reaction condition: $1 \mathrm{ml} 0.1 \mathrm{M} \mathrm{H}_{2} \mathrm{O}_{2}, 1 \mathrm{ml}$ hydrogels

concentrations. However, high $\mathrm{Co}^{2+}$ concentration was not favored for long-lasting time and hydrogel formation. Besides, it was also found that $\mathrm{CL}$ signal was highly dependent on the concentration of $\mathrm{H}_{2} \mathrm{O}_{2}$ (Supplementary Fig. 8). The CL intensity and the duration time increased with increasing the concentration of $\mathrm{H}_{2} \mathrm{O}_{2}$ up to $0.1 \mathrm{M}$. However, when the concentration of $\mathrm{H}_{2} \mathrm{O}_{2}$ was higher than $0.1 \mathrm{M}$, the CL intensity was slightly down and the
$\mathrm{CL}$ was instable. It is possible that the oxygen bubbles due to $\mathrm{H}_{2} \mathrm{O}_{2}$ decomposition had an effect on the stability of the CL reaction. The effect of $\mathrm{pH}$ of $\mathrm{H}_{2} \mathrm{O}_{2}$ solution on the $\mathrm{CL}$ emission was studied in the $\mathrm{pH}$ range of 7.0-13.0. The CL emission could still be observed under neutral conditions. The CL intensities remained almost constant upon increasing $\mathrm{pH}$ values, and the optimal time for plateau emission was at $\mathrm{pH} \quad 10.88$ 
(Supplementary Fig. 9). Under optimal conditions, digital camera was used to record CL emission image in real time when $\mathrm{H}_{2} \mathrm{O}_{2}$ solution was either mixed fully with $\mathrm{ABEI} / \mathrm{Co}^{2+} / \mathrm{CS}$ hydrogels (Fig. 4a vial A) or added into $\mathrm{ABEI} / \mathrm{Co}^{2+} / \mathrm{CS}$ hydrogels directly (Fig. $4 \mathrm{a}$ vial B). Figures $4 \mathrm{~b}, 4 \mathrm{c}$ also shows the CL intensity as a function of time over $150 \mathrm{~h}$ (the CL intensity was calculated as described in Supplementary Note 1). Both of cases showed intensive emission, which was even visible in a dark room with naked eyes. It is noteworthy that CL could last for more than 150 h. The CL spectra of ABEI/Co ${ }^{2+} / \mathrm{CS}$ hydrogels with $\mathrm{H}_{2} \mathrm{O}_{2}$ at different times were also measured, as shown in Supplementary Fig. 10. No obvious change in CL spectra was observed.

\section{Discussion}

Such intensive and long-lasting emission of $\mathrm{ABEI} / \mathrm{Co}^{2+} / \mathrm{CS}$ hydrogels could be ascribed to the following reasons. As reported, metal ions, such as $\mathrm{Co}^{2+}$, could be highly adsorbed by chitosan by forming coordination bonds via hydroxyl and amine groups ${ }^{20,21}$. Metal ions in the chitosan hydrogels could function as stabilizing linkages to prevent gel dissolution ${ }^{22}$. Thus, it may be suggested that $\mathrm{Co}^{2+}$ coordinates with the skeleton of the CS hydrogels and most of $\mathrm{Co}^{2+}$ exists in the CS phase. When the ABEI/Co ${ }^{2+} / \mathrm{CS}$ hydrogels were centrifuged, $\mathrm{Co}^{2+}$ and ABEI concentration in supernatant were determined to be $6.41 \times 10^{-5}$ and $3.14 \mathrm{mM}$, respectively, as shown Supplementary Table 1 and Note 2. $\mathrm{Co}^{2+}$ and ABEI concentration in $\mathrm{ABEI} / \mathrm{Co}^{2+} / \mathrm{CS}$ hydrogels were $3.51 \times 10^{-2}$ and $3.51 \mathrm{mM}$, respectively. The results demonstrated that $0.18 \% \mathrm{Co}^{2+}$ and $89.48 \%$ ABEI existed in aqueous phase. Thus almost all of $\mathrm{Co}^{2+}$ was immobilized at the skeleton of the CS hydrogels. The porous network structure possessed micro/nanosized pores and acted as a water-absorbing sponge, which allowed high concentration of ABEI to be loaded into the pores of the hydrogels. The uniform dispersion of ABEI in the porous network structure of hydrogels was confirmed by the fluorescence imaging of $\mathrm{ABEI} / \mathrm{Co}^{2+} / \mathrm{CS}$ hydrogels (Supplementary Fig. 11). Vial $\mathrm{B}$ in Fig. 4a shows the real-time reaction which involves adding $1 \mathrm{ml} \mathrm{H}_{2} \mathrm{O}_{2}$ solution onto the top of $1 \mathrm{ml}$ hydrogels without further agitation. At the beginning, the $\mathrm{CL}$ reaction merely occurred at the interface between $\mathrm{ABEI} / \mathrm{Co}^{2+} / \mathrm{CS}$ hydrogels and $\mathrm{H}_{2} \mathrm{O}_{2}$ solution. Gradually, the $\mathrm{H}_{2} \mathrm{O}_{2}$ diffused into the hydrogels and more $\mathrm{CL}$ emission could be seen from the hydrogels. Due to the slow diffusion in hydrogels, it took $3-6 \mathrm{~h}$ for the top layer $\mathrm{H}_{2} \mathrm{O}_{2}$ to reach the bottom of the hydrogels (Fig. 4a, vial $\mathrm{B}$ ), making the whole hydrogel lighting up. The slight degradation of the hydrogels was observed to produce some hydrogels fragments, which may speed up the diffusion and mixing process. Alternatively, if the hydrogels were fully mixed with $\mathrm{H}_{2} \mathrm{O}_{2}$ solution at first, $\mathrm{CL}$ emission appeared immediately in the entire bulk solution (Fig. 4a, vial A). The diffusion coefficient of $\mathrm{H}_{2} \mathrm{O}_{2}$ in the CS hydrogels was determined, as shown in Supplementary Fig. 12, Table 2 and Note 3. The results demonstrated that the diffusion coefficient of $\mathrm{H}_{2} \mathrm{O}_{2}$ in the CS hydrogels was more than one order of magnitude lower than that in a buffer solution, supporting the slow diffusion of $\mathrm{H}_{2} \mathrm{O}_{2}$ in hydrogels. The superior CL properties of the as-prepared hydrogels are derived from the synergistic effect of ABEI, $\mathrm{Co}^{2+}$ and porous network structure of $\mathrm{ABEI} / \mathrm{Co}^{2+} / \mathrm{CS}$ hydrogels. It is suggested that $\mathrm{Co}^{2+}$ located at the skeleton of CS hydrogels is active site of the CL reaction, which is surrounded by ABEI molecules in pores of the hydrogels. When $\mathrm{H}_{2} \mathrm{O}_{2}$ slowly diffuses to the active site, $\mathrm{Co}^{2+}$ as a catalyst would react with $\mathrm{H}_{2} \mathrm{O}_{2}$ to produce a highly reactive hydroxyl radical $\mathrm{OH}^{\bullet}$, followed by the reaction with ABEI anion and $\mathrm{HO}_{2}{ }^{-}$to facilitate the formation of $\mathrm{ABEI}$ radicals and $\mathrm{O}_{2}{ }^{\bullet-}$. Finally, $\mathrm{ABEI}$ radicals react with $\mathrm{O}_{2}{ }^{\bullet-}$ to generate strong $\mathrm{CL}$ emission ${ }^{15}$. Because of the slow diffusion rate of $\mathrm{H}_{2} \mathrm{O}_{2}$ in hydrogels with high viscosity and micro/nano-sized pores, the CL reaction is a slow-diffusion-controlled process and could proceed for several days. $\mathrm{Co}^{2+}$ exhibited the strongest catalytic effect for the CL system, which may be due to that $\mathrm{Co}^{2+}$ complex demonstrated the strongest decomposition ability of hydrogen peroxide among transition metal ions ${ }^{23,24}$ and was the best catalyst for luminol and its analogue $\mathrm{CL}$ reactions ${ }^{19}$. It was reported that $\mathrm{Co}^{2+}$ in the solutions showed very low catalytic activity for the decomposition of $\mathrm{H}_{2} \mathrm{O}_{2}$. Complexation and heterogenization of $\mathrm{Co}^{2+}$ enhance the catalytic activity of $\mathrm{Co}^{2+}$ on the decomposition of $\mathrm{H}_{2} \mathrm{O}_{2}{ }^{25}$. It was also reported that the attachment of catalyst metal complex to a rigid polymer resulted in an increase in the catalytic activity and the stability of catalyst ${ }^{26,27}$. This is because active site on the polymer was isolated and inactive reactions of catalyst metal ions in the homogeneous phase were prevented ${ }^{26,27}$. Thus, in this case, $\mathrm{Co}^{2+}$ coordinated by hydroxyl and amine groups at the skeleton of CS hydrogels exhibited unique heterogeneous catalytic activity on the CL reaction, leading to intensive emission. The light emission could last for more than $150 \mathrm{~h}$, implying that catalyst $\mathrm{Co}^{2+}$ could maintain catalytic activity for a long time. The excellent stability of catalyst $\mathrm{Co}^{2+}$ in the hydrogels may be due to the stabilization effect of polymer CS. Accordingly, high efficiency and excellent stability of catalyst $\mathrm{Co}^{2+}$ and the slow diffusion rate of $\mathrm{H}_{2} \mathrm{O}_{2}$ in hydrogels with high viscosity and micro/nano-sized pores resulted in the intensive and long-lasting CL emission. It is well known that firefly BL can produce intensive and long-lasting emission. Thus, the intensive and long-lasting CL emission from the hydrogels mimics firefly $\mathrm{BL}$ in terms of intensity and duration time. Since $\mathrm{Co}^{2+}$ was capable of maintaining catalytic activity for a long time and demonstrated high catalytic efficiency due to the hydrogels, the catalytic characteristic of $\mathrm{Co}^{2+}$ in our system are similar to those of enzyme associated with firefly $\mathrm{BL}^{17}$.

In conclusion, we have demonstrated firefly-mimicking intensive and long-lasting $\mathrm{CL} \mathrm{ABEI} / \mathrm{Co}^{2+} / \mathrm{CS}$ hydrogels. The light emission could be observed even by naked eyes in a dark room and lasted for over $150 \mathrm{~h}$ when the hydrogels reacted with $\mathrm{H}_{2} \mathrm{O}_{2}$. The intensive and long-lasting CL emission was attributed to the synergistic effect of $\mathrm{Co}^{2+}$, ABEI and the porous network structure of the hydrogels through a slow-diffusion-controlled heterogeneous catalytic reaction. Using the low-concentration $\mathrm{Co}^{2+}$ as catalyst with high efficiency, CL emission of the as-prepared $\mathrm{ABEI} / \mathrm{Co}^{2+} / \mathrm{CS}$ hydrogels mimics firefly BL system in terms of intensity, duration time and catalytic characteristic. Such intensive and long-lasting $\mathrm{CL}$ emission with long-lasting mechanism is distinctly different from those of existing enzyme-involved CL and peroxyoxalate ester CL systems. The hydrogels can be used as cold light source in emergency situations, decorative entertainment, and underwater lighting. Compared with the commercial light sources whose emission duration can only reach $10-12 \mathrm{~h}$, our hydrogels achieve a great improvement, which can produce CL emission for over $150 \mathrm{~h}$. Our hydrogels are also environment-friendly and cost-effective. Moreover, the $\mathrm{ABEI} / \mathrm{Co}^{2+} / \mathrm{CS}$ hydrogels may find future applications in biosensors, microchips, bioassays and bioimaging, due to the hydrogel's excellent biocompatibility ${ }^{28-31}$ and intensive and long-lasting CL emission.

\section{Methods}

Chemicals and materials. A $4.0 \mathrm{mM}$ ABEI stock solution was prepared by dis solving ABEI (TCI, Japan) in $0.1 \mathrm{M} \mathrm{NaOH}$ solution. Chitosan (Mv> $1000 \mathrm{kDa}$ degree of deacytylation $>90 \%$ ) was obtained from shanghai reagent (Shanghai, China). Working solutions of $\mathrm{H}_{2} \mathrm{O}_{2}$ were prepared fresh daily from $30 \%$ (v/v) $\mathrm{H}_{2} \mathrm{O}_{2}$ (Xin Ke Electrochemical Reagent Factory, Bengbu, China). All other reagents were of analytical grade. Ultrapure water was prepared by a Milli-Q system (Millipore, France) and used throughout. All glassware used in the following procedures was cleaned in a bath of freshly prepared $\mathrm{HNO}_{3}-\mathrm{HCl}(3: 1, \mathrm{v} / \mathrm{v})$, rinsed thoroughly with ultrapure water, and dried prior to use. 
Synthesis of $\mathbf{A B E l} / \mathrm{Co}^{2+} / \mathrm{CS}$ hydrogels. $\mathrm{Co}^{2+} / \mathrm{CS}$ hydrogels were synthesized through the freezing-thawing method as previously reported with some modifications ${ }^{9}$. Chitosan powders were dispersed into $15 \mathrm{ml}$ alkaline solution containing $\mathrm{LiOH} / \mathrm{KOH} / \mathrm{urea} / \mathrm{H}_{2} \mathrm{O}$ in a ratio of 4.5: 7: $8: 80.5$ by weight. $0.6 \mathrm{ml}$ of $\mathrm{CoCl}_{2}$ $(1,5,10,20,30 \mathrm{mM})$ was added to the above solution with stirring for $5 \mathrm{~min}$, and then were stored under refrigeration until completely frozen. After that, the frozen solid was fully thawed. The $\mathrm{Co}^{2+} / \mathrm{CS}$ hydrogels with $2.5 \mathrm{wt} \%$ of chitosan were obtained. Next, $1.5 \mathrm{ml}$ of ABEI $(0.04,0.4,4$ or $40 \mathrm{mM})$ was added to the $\mathrm{Co}^{2+} / \mathrm{CS}$ hydrogels and stirred for $5 \mathrm{~h}$. Finally, the $\mathrm{ABEI} / \mathrm{Co}^{2+} / \mathrm{CS}$ hydrogels were obtained. The as-prepared $\mathrm{Co}^{2+} / \mathrm{CS}$ and $\mathrm{ABEI} / \mathrm{Co}^{2+} / \mathrm{CS}$ hydrogels were stored at $4{ }^{\circ} \mathrm{C}$.

Characterization and property of $\mathrm{ABEI} / \mathrm{Co}^{2+} / \mathrm{CS}$ hydrogels. The as-synthesized hydrogels were characterized by SEM, rheological measurements, ICP-AES, inductively coupled plasma mass force microscopy (ICP-MS), UV-visible absorption spectra, microscope imaging, and CL spectra. For the SEM analysis, the $\mathrm{Co}^{2+} / \mathrm{CS}$ hydrogels were diluted 10 times with an alkaline solution containing $\mathrm{LiOH} / \mathrm{KOH} / \mathrm{urea} / \mathrm{H}_{2} \mathrm{O}$ with a ratio of 4.5: 7: 8: 80.5 by weight. The dilution was refrigerated to form frozen solid, then put into the lyophilizer under a condensing temperature of $-50^{\circ} \mathrm{C}$ and vacuum degree of $10 \mathrm{~Pa}$. After $48 \mathrm{~h}$, freeze-dried $\mathrm{Co}^{2+} / \mathrm{CS}$ hydrogels were obtained. A thin-layer of freeze-dried $\mathrm{Co}^{2+} / \mathrm{CS}$ hydrogels were deposited onto the conducting film. The morphology of the $\mathrm{Co}^{2+} / \mathrm{CS}$ hydrogels was measured by SEM. SEM images were obtained by a JEOL JEM-6700F microscope (Japan). The porosity of the hydrogels was calculated according to the equation: porosity $=[($ skeletal density-bulk density $) /$ skeletal density] $\times 100 \%{ }^{32}$. Specifically, the $\mathrm{ABEI} / \mathrm{Co}^{2+} / \mathrm{CS}$ hydrogels were put in a bottle. After freeze-drying process as that in the treatment of the hydrogels for SEM, the weight of freeze-dried ABEI/ $\mathrm{Co}^{2+} / \mathrm{CS}$ hydrogels was $0.4122 \mathrm{~g}$, and the volume was $2 \mathrm{~cm}^{3}$. Thus, the density of freeze-dried hydrogels (bulk density) was calculated to be $0.2061 \mathrm{~g} \mathrm{ml}^{-1} .1 \mathrm{~g}$ of chitosan powders was added to $5 \mathrm{ml}$ of ethanol in the graduated cylinder to obtain a solution with total volume of $5.7 \mathrm{ml}$ (chitosan was not dissoluble in ethanol). Thus, the density of chitosan (skeletal density) was calculated to be $1.4286 \mathrm{~g} \mathrm{~cm}^{-3}$. Porosity could be computed according to above equation. Rheological measurements were conducted on a TA AR-G2 rheometer using a coneplate of $40 \mathrm{~mm}$ diameter with a cone angle of $1 \%$. ICP-AES was obtained on an OPTIMA 7000DV atomic emission spectrometer. ICP-MS was measured on PlasmaQuad 3 Thermo VG (UK). UV-visible absorption spectra were obtained using UV-visible spectrophotometer (Agilent 8453, USA). CL spectra were measured on a model F-7000 spectrofluorophotometer when the Xe lamp was turned off (Hitachi, Japan). Fluorescence imaging was obtained on fluorescence microscope (Olympus DP72). CL gel imaging micrograph was performed on ChemiDoc XRS System (BIO-RAD, America). Digital photos were obtained on D7200 Nikon, and every picture was taken by using a delay of $30 \mathrm{~s}$. The static injection CL detection was conducted on a BPCL Luminescence Analyzer (Beijing, China) with a fixed PMT voltage of -550 V. For a typical CL measurement, $100 \mu \mathrm{l}$ of ABEI/ $\mathrm{Co}^{2+} / \mathrm{CS}$ hydrogels was added to a cylindrical cell, then $100 \mu \mathrm{l}$ of $0.1 \mathrm{M}$ $\mathrm{H}_{2} \mathrm{O}_{2}$ in $\mathrm{B}-\mathrm{R}$ buffer $(\mathrm{pH}=10.88)$ was injected into the cell to initiate the CL reaction. The $\mathrm{CL}$ intensity during the reaction along with time was recorded by the luminescence analyzer.

Data availability. The authors declare that all the data are available within the article file and its Supplementary Information or from the corresponding author upon reasonable request.

Received: 1 April 2017 Accepted: 15 August 2017

Published online: 17 October 2017

\section{References}

1. Diaz, J. M. et al. Species-specific control of external superoxide levels by the coral holobiont during a natural bleaching event. Nat. Commun. 7, 13801 (2016).

2. Clough, J. M., Balan, A., van Daal, T. L. J. \& Sijbesma, R. P. Probing force with mechanobase-induced chemiluminescence. Angew. Chem. Int. Ed. 55, 1445-1449 (2016).

3. Shuhendler, A. J., Pu, K., Cui, L., Uetrecht, J. P. \& Rao, J. Real-time imaging of oxidative and nitrosative stress in the liver of live animals for drug-toxicity testing. Nat. Biotechnol. 32, 373-380 (2014).

4. Baumes, J. M. et al. Storable, thermally activated, near-infrared chemiluminescent dyes and dye-stained microparticles for optical imaging. Nat. Chem. 2, 1025-1030 (2010).

5. Roda, A., Guardigli, M., Michelini, E., Mirasoli, M. \& Pasini, P. Peer reviewed: analytical bioluminescence and chemiluminescence. Anal. Chem. 75, 463A-470A (2003).

6. Roda, A. et al. Portable device based on chemiluminescence lensless imaging for personalized diagnostics through multiplex bioanalysis. Anal. Chem. 83, 3178-3185 (2011).
7. Adams, S. T., Mofford, D. M., Reddy, G. S. K. K. \& Miller, S. C. Firefly luciferase mutants allow substrate-selective bioluminescence imaging in the mouse brain. Angew. Chem. Int. Ed. 55, 4943-4946 (2016).

8. Hananya, N., Boock, A. E., Boock, C. R., Satchi-Fainaro, R. \& Shabat, D. Remarkable enhancement of chemiluminescent signal by dioxetane-fluorophore conjugates: turn-on chemiluminescence probes with color modulation for sensing and imaging. J. Am. Chem. Soc. 138, 13438-13446 (2016).

9. Lee, D. et al. In vivo imaging of hydrogen peroxide with chemiluminescent nanoparticles. Nat. Mater. 6, 765-769 (2007).

10. Kapeluich, Y. L., Rubtsova, M. Y. \& Egorov, A. M. Enhanced chemiluminescence reaction applied to the study of horseradish peroxidase stability in the course of p-iodophenol oxidation. J. Biolumin. Chemilumin. 12, 299-308 (1997).

11. Duan, J., Liang, X., Cao, Y., Wang, S. \& Zhang, L. High strength chitosan hydrogels with biocompatibility via new avenue based on constructing nanofibrous architecture. Macromolecules 48, 2706-2714(2015).

12. Sun, G. M., Zhang, X. Z. \& Chu, C. C. Formulation and characterization of chitosan-based hydrogel films having both temperature and $\mathrm{pH}$ sensitivity. J. Mater. Sci. Mater. Med. 18, 1563-1577 (2007).

13. Qu, X., Wirsen, A. \& Albertsson, A. C. Novel pH-sensitive chitosan hydrogels: swelling behavior and states of water. Polymer 41, 4589-4598 (2000).

14. Tsai, T. N. et al. Novel protein-loaded chondroitin sulfate- $N$-[(2-hydroxy-3trimethylammonium) propyl] chitosan nanoparticles with reverse zeta potential: preparation, characterization, and ex vivo assessment. Mater. Chem. B 3, 8729-8737 (2015).

15. Liu, M. et al. Gold nanoparticles bifunctionalized by chemiluminescence reagent and catalyst metal complexes: synthesis and unique chemiluminescence property. Anal. Chem. 86, 2857-2861 (2014).

16. Dowd, C. D. \& Paul, D. B. Synthesis and evaluation of diary1 oxalate esters for low-intensity chemiluminescent illumination. Aust. J. Chem. 37, 73-86 (1984).

17. Ignowski, J. M. \& Schaffer, D. V. Kinetic analysis and modeling of firefly luciferase as a quantitative reporter gene in live mammalian cells. Biotechnol. Bioeng. 86, 827-834 (2004).

18. Feeney, K. A., Putker, M., Brancaccio, M. \& O’Neill, J. S. In-depth characterization of firefly luciferase as a reporter of circadian gene expression in mammalian cells. J. Biol. Rhythm. 31, 540-550 (2016).

19. Burdo, T. G. \& Seitz, W. R. Mechanism of cobalt catalysis of luminol chemiluminescence. Anal. Chem. 47, 1639-1643 (1975).

20. Zhang, L., Zeng, Y. \& Cheng, Z. Removal of heavy metal ions using chitosan and modified chitosan: A review. J. Mol. Liq. 214, 175-191 (2016).

21. Nie, J., Wang, Z. \& Hu, Q. Difference between Chitosan Hydrogels via Alkaline and Acidic Solvent Systems. Sci. Rep. 6, 1-8 (2016).

22. Bhattarai, N., Gunn, J. \& Zhang, M. Chitosan-based hydrogels for controlled, localized drug delivery. Adv. Drug Delivery Rev. 62, 83-99 (2010).

23. Shi, J., Lu, C., Yan, D. \& Ma, L. High selectivity sensing of cobalt in HepG2 cells based on necklace model microenvironment-modulated carbon dot-improved chemiluminescence in Fenton-like system. Biosens. Bioelectron. 45, 58-64 (2013).

24. Lin, J. M., Shan, X. Q., Hanaoka, S. \& Yamada, M. Luminol chemiluminescence in unbuffered solutions with a cobalt(II)-ethanolamine complex immobilized on resin as catalyst and its application to analysis. Anal. Chem. 73, 5043-5051 (2001).

25. Shivankar, V. S. \& Thakkar, N. V. Decomposition of hydrogen peroxide in presence of mixed ligand cobalt (II) and nikel (II) complexes as catalysts. J. Sci. Ind. Res. 64, 496-503 (2005).

26. Chen, C., Sun, J., Li, H. \& He, B. Polymer effects on polymer-supported transition metal catalysts. Ion Exchange \& Adsorption 7, 227-236 (1991).

27. Grubbs, R. H., Lau, C. P., Cukier, R. \& Brubaker, C. Polymer attached metallocenes. Evidence for site isolation. J. Am. Chem. Soc. 99, 4517-4518 (1977).

28. Seliktar, D. Designing cell-compatible hydrogels for biomedical applications. Science 336, 1124-1128 (2012).

29. Ashley, G. W., Henise, J., Reid, R. \& Santi, D. V. Hydrogel drug delivery system with predictable and tunable drug release and degradation rates. Proc. Natl. Acad. Sci. U. S. A. 110, 2318-2323 (2013).

30. Kamata, H., Akagi, Y., Kayasuga-Kariya, Y., Chung, U. \& Sakai, T. "Nonswellable" hydrogel without mechanical hysteresis. Science 21, 873-875 (2014).

31. Li, J. \& Mooney, D. J. Designing hydrogels for controlled drug delivery. Nat. Rev. Mater. 1, 1-17 (2016).

32. Ferreira, L., Gila, M. H., Cabritab, A. M. S. \& Dordickc, J. S. Biocatalytic synthesis of highly ordered degradable dextran-based hydrogels. Biomaterials 26, 4707-4716 (2005). 


\section{Acknowledgements}

The support of this research by the National Key Research and Development Program of China (Grant No. 2016YFA0201300) and the National Natural Science Foundation of China (Grant Nos. 21527807 and 21475120) are gratefully acknowledged. We thank Prof. K. Nakashima and Dr. E. Michelini for discussing the mechanism of peroxyoxalate ester CL system and firefly bioluminescence system. We are gratefully acknowledged for Prof. Y.X. Chen and Ms. J.J. Li to provide the experimental device for the measurement of diffusion coefficients of $\mathrm{H}_{2} \mathrm{O}_{2}$ in the hydrogels. We also thank Prof. Z.X. Deng for the discussion on diffusion coefficients, enzyme catalysis and the porosity of the hydrogels.

\section{Author contributions}

Y.L., W.S. and Q.L. contributed equally to this work. Y.L. and W.S. designed the project. Y.L. and Q.L. carried out the experimental work and writing of original draft J.S. measured the diffusion coefficients of $\mathrm{H}_{2} \mathrm{O}_{2}$ in the hydrogels. W.W. and L.G. helped to complete the experimental work. M.M. was involved in studies on the long-lasting CL mechanism. W.S., J.S., W.W. and M.M. were also involved in writing of original draft. H.C. designed and directed the project and wrote the manuscript.

\section{Additional information}

Supplementary Information accompanies this paper at doi:10.1038/s41467-017-01101-6.
Competing interests: The authors declare no competing financial interests.

Reprints and permission information is available online at http://npg.nature.com/ reprintsandpermissions/

Publisher's note: Springer Nature remains neutral with regard to jurisdictional claims in published maps and institutional affiliations.

(c) (i) Open Access This article is licensed under a Creative Commons Attribution 4.0 International License, which permits use, sharing, adaptation, distribution and reproduction in any medium or format, as long as you give appropriate credit to the original author(s) and the source, provide a link to the Creative Commons license, and indicate if changes were made. The images or other third party material in this article are included in the article's Creative Commons license, unless indicated otherwise in a credit line to the material. If material is not included in the article's Creative Commons license and your intended use is not permitted by statutory regulation or exceeds the permitted use, you will need to obtain permission directly from the copyright holder. To view a copy of this license, visit http://creativecommons.org/ licenses/by/4.0/.

(C) The Author(s) 2017 